\title{
Beyond the Instinct-Inference Dichotomy: A Unified Interpretation of Peirce's Theory of Abduction \\ Mousa Mohammadian (mmohamma@nd.edu)
}

\begin{abstract}
I examine and resolve an exegetical dichotomy between two main interpretations of Peirce's theory of abduction, namely, the Generative Interpretation and the Pursuitworthiness Interpretation. According to the former, abduction is the instinctive process of generating explanatory hypotheses through a mental faculty called insight. According to the latter, abduction is a rule-governed procedure for determining the relative pursuitworthiness of available hypotheses and adopting the worthiest one for further investigation — such as empirical tests—based on economic considerations. It is shown that the Generative Interpretation is inconsistent with a fundamental fact of logic for Peirce-i.e., abduction is a kind of inference-and the Pursuitworthiness Interpretation is flawed and inconsistent with Peirce's naturalistic explanation for the possibility of science and his view about the limitations of classical scientific method. Changing the exegetical locus classicus from the logical form of abduction to insight and economy of research, I argue for the Unified Interpretation according to which abduction includes both instinctive hypothesesgeneration and rule-governed hypotheses-ranking. I show that the Unified Interpretation is immune to the objections raised successfully against the Generative and the Pursuitworthiness interpretations.
\end{abstract}

Key Words: Abduction, Insight, Economy of Research, Explanation, Instinct, Inference, Reasoning, Scientific Inquiry 


\section{Introduction}

It took about four decades for Peirce to fully develop his theory of abduction. Throughout his career, he came up with different accounts of abduction and, as we shall see, sometimes he was very critical of his earlier views. ${ }^{1}$ His works undoubtedly show the beauty of the generation and evolution of an original idea. ${ }^{2}$ But the variety of interpretations suggested by scholars show how difficult it is to find out what his theory of abduction really is. Focusing primarily on Peirce's mature views, McKaughan (2008) distinguishes three competing interpretations of Peirce's theory of abduction:

(1) The Generative Interpretation: abduction is the type of inference (or reasoning) ${ }^{3}$ through which one generates explanatory hypotheses for a surprising phenomenon.

(2) The Justificatory Interpretation: abduction is the type of inference used to justify claims concerning the probable truth of explanatory hypotheses.

(3) The Pursuitworthiness Interpretation: abduction is the type of reasoning through which, faced with several explanatory hypotheses for a phenomenon, one evaluates which hypothesis should be adopted for further considerations, such as empirical tests. That is, abduction determines the relative pursuitworthiness of available hypotheses.

McKaughan strongly rejects the Justificatory Interpretation, holds that "the Generative Interpretation mischaracterizes crucial features of Peirce's view" (2008, 450), and suggests that "At the very least, ... the Pursuitworthiness Interpretation will have to be part of any attempt to come to grips with Peirce’s wide ranging remarks about abduction” $(2008,459)$.

I agree with McKaughan that the Justificatory Interpretation misrepresents Peirce's view of abduction. However, in this paper I argue that (i) one of the best known objections against the Generative Interpretation, i.e., its incompatibility with the logical form of abduction, is misguided; (ii) the Pursuitworthiness Interpretation is a deeply flawed and incomplete interpretation of abduction; (iii) 'the Generative Interpretation vs. the Pursuitworthiness Interpretation' is a false exegetical dichotomy; and finally (iv) the right interpretation of abduction should unify the Generative Interpretation and the Pursuitworthiness Interpretation. I provide this Unified Interpretation, show its advantages over the Generative Interpretation and the Pursuitworthiness Interpretation, and defend it against possible objections.

In Section 2, I discuss the Generative Interpretation and two objections that are raised against it. Section 3 examines the Pursuitworthiness Interpretation and shows that although it is immune to 
the main objection raised against the Generative Interpretation, it is still a flawed and incomplete interpretation of abduction. In particular, I argue that the Pursuitworthiness Interpretation is inconsistent with some crucial aspects of Peirce's general philosophy of science, namely, his naturalistic explanation for the possibility of science and his view about the limitations that 'classical' scientific method imposes on the depth and the scope of scientific knowledge. In Section 3, I introduce the Unified Interpretation as the right interpretation of Peirce's theory of abduction, argue for its coherence with Peirce's general account of reasoning and his philosophy of science, support it with textual evidence, and show that it does not have the problems that the Generative Interpretation and the Pursuitworthiness Interpretation have.

\section{The Generative Interpretation of Abduction}

\subsection{Prelude: In Newton's Garden}

The story goes that when Newton observed an apple's falling from a tree, he thought to himself: 'why should that apple descend perpendicularly to the ground rather than going sideways or upwards?' After a deep meditation, Newton's friend William Stukeley reports, a sudden Eureka moment came:

there must be a drawing power in matter. \& the sum of the drawing power in the matter of the earth must be in the earth's center ... therefore dos this apple fall perpendicularly or toward the center. if matter thus draws mater; it must be in proportion of its quantity. therefore the apple draws the earth, as well as the earth draws the apple. (cited from Martínez 2011, 49-50)

And universal gravitation was discovered!

\subsection{Abduction is the Instinctive Generation of Explanatory Hypotheses}

Through what kind of reasoning does a scientist discover a hypothesis or a theory that explains a phenomenon? For instance, what kind of reasoning led Newton to the discovery of universal gravitation? Proponents of the Generative Interpretation believe that the answer is abduction. An example of the Generative Interpretation can be found in Hanson's Patterns of Discovery (1958) where he claims that Kepler's discovery of the elliptical shape of the orbits of planets was an instance of abductive inference. Hintikka (1998), too, holds that Peircean abduction is the exemplar of (if not identical with) ampliative reasoning. More recently, Campos has claimed that abduction is "an indepth account of the process of generating explanatory hypotheses" $(2009,420)$. Other examples of 
the Generative Interpretation include Davis (1972, chap. II), Turrisi (1990), Burton (2000), and Minnameier (2004).

After observing a "surprising" $(5.189,1903)^{4}$ or unexpected phenomenon, scientists seek to resolve the wonder by explaining the phenomenon. An explanation is a proposition that "would lead to the prediction of the observed facts, either as necessary consequences or at least as very probable under the circumstances" $(7.202,1901)$. According to the Generative Interpretation, Peirce holds that "Abduction is the process of forming an explanatory hypothesis" $(5.171,1903)$ and it is the only type of inference that is "originary" $(2.96,1902)$, and "starts a new idea" $(5.145,1903)$.

But Peirce knows very well that for a given phenomenon, one can come up with as many explanations as one wishes and the explanations can be as 'wild' as possible so long as one can imagine some way in which the explanations can make the explanandum a matter of course:

A physicist comes across some new phenomenon in his laboratory. How does he know but the conjunctions of the planets have something to do with it or that it is not perhaps because the dowager empress of China has at that same time a year ago chanced to pronounce some word of mystical power ... Think of what trillions of trillions of hypotheses might be made of which one only is true; $(5.172,1903)$

But in practice, scientists only invent a small number of candidate explanations without even thinking about 'wild' hypotheses. In Peirce's own words "trillions of trillions of hypotheses might be made ... [but] after two or three or at the very most a dozen guesses, the physicist hits pretty nearly on the correct hypothesis" $(5.172,1903)$.

Two questions should be addressed here. First, how do scientists come up with new explanatory hypotheses? Second, why do scientists come up only with a handful of reasonable explanatory hypotheses? Peirce provides one answer for both questions: humans (but not only humans) possess a mental faculty of guessing called insight which enables them not only to guess (i.e., to generate) explanatory hypotheses, but also to generate only plausible hypotheses. In other words, insight has two functions. As the "faculty of divining the ways of Nature" $(5.173,1903)$ or the "guessinginstinct" (6.531, 1901; 7.46, 1907), it performs an inventive function through hypothesesgeneration. But as a tendency "toward a positive truth" (5.591, 1903), "to conjecture rightly" $(7.679,1903)$, or "toward preferring truthful hypotheses" $(7.680,1903)$, it performs a restrictive function by only generating reasonable hypotheses. 
In its restrictive function, insight is "not strong enough to be oftener right than wrong, but strong enough not to be overwhelmingly more often wrong than right" $(5.173,1903)$. As a result, we should put insight's guesses to the test. For this reason, first the testable consequences of the guessed hypotheses should be drawn through deduction. Then the consequences should be tested empirically which, for Peirce, constitutes induction $(5.145,1903)$. These three types of inference, i.e., abduction, deduction, and induction, are three steps and constituents of scientific inquiry.

Two important objections have been raised against the Generative Interpretation. First, there is a group of 'formal objections' stating that it is unable to make sense of the logical form of abduction. Second, according to a 'non-formal objection', it is inconsistent with Peirce's general account of reasoning. Let's examine these objections in more detail.

\subsection{The Formal Objections against the Generative Interpretation}

In his Harvard Lectures on Pragmatism (1903), Peirce states that abduction has "a definite logical form":

The surprising fact, $\mathrm{C}$, is observed;

But if A were true, $\mathrm{C}$ would be a matter of course,

Hence, there is reason to suspect that $\mathrm{A}$ is true. $(5.189,1903)$

According to the first formal objection against the Generative Interpretation, introduced by Frankfurt (1958), hypothesis $A$ (namely, the explanation of the surprising fact $C$ ) first appears in the second premise of the logical form of abduction. This means that $A$ is generated before the conclusion was drawn. So as opposed to what the Generative Interpretation indicates, generation of explanation $A$ is not a result of abduction.

Anderson (1986; 1987, 34-35) has a response to this objection. He argues that since $A$ in the second premise is identical with $A$ in the conclusion, they are arrived at simultaneously and none of them has temporal priority to the other; rather $A$ in the second premise is only logically prior to the $A$ in the conclusion. So Frankfurt's claim that that since $A$ appears in the second premise it "must have been invented before the conclusion was drawn" (Frankfurt 1958, 594, my emphasis) is false.

By showing that appearance of $A$ in the second premise does not require its discovery before the conclusion, Anderson reveals a weakness in Frankfurt's objection. Yet, he is unsuccessful to completely defuse the objection, because his response still allows the possibility of coming up with $A$ 
before the second premise and the conclusion of abduction. That is, it allows the possibility of $A$ not being the result of abduction. This is inconsistent with Peirce's view that only abduction can generate new ideas.

This brings us to the second and the more powerful formal objection (Hoffmann 1999, 27879): while the Generative Interpretation claims that abduction is all about generating hypothesis $A$, the logical form of abduction says nothing about $A$ 's generation at all. Rather, it simply describes $A$ 's relationship with the surprising fact and its probable truth. For example, that the universal gravitation hypothesis explains the apple's falling from the tree and (hence) it is probably true, says nothing about how Newton came up with this idea. So the Generative Interpretation, according to which abduction is the instinctive generation of explanatory hypotheses, cannot make any sense of the logical form of abduction.

\subsection{The Non-formal Objection against the Generative Interpretation}

Based upon an essential discrepancy between hypothesis-generation and reasoning (or inference) in Peirce's works, some opponents of the Generative Interpretation raise a non-formal objection against this interpretation (Burks 1946; Kapitan 2000; McKaughan 2008). They argue that on the one hand, Peirce holds that hypotheses-generation is an instinctive act, because it is done by insight which is an instinct—the "guessing-instinct" $(6.531,1901 ; 7.46,1907)$ - similar to animal instincts, such as a bird's instincts of singing and flying $(7.48,1907)$ or a chicken's instinct of pecking $(6.591$, 1903). As a result, similar to all instincts, insight does not operate through "a self-controlled and critical logic" $(5.173,1903)$ and hence an inquirer "cannot give any exact reason for his best guesses" $(5.173,1903)$ and contents himself to call them "reasonable" or "plausible" $(5.174,1903 ; 8.223$, 1910; EP2.441, 1908). On the other hand, Peirce holds that reasoning "is essentially deliberate and self-controlled" $(5.108,1903)$. Thus, one can always provide reason(s) for adopting a belief that is a result of an inference or reasoning $(7.458,1902)$. This is a fatal objection against the Generative Interpretation. For if abduction is hypotheses-generation, as the Generative Interpretation suggests, and hypotheses-generation cannot be an inference, then abduction is not an inference. But it is a fundamental fact of logic for Peirce that abduction is a type of inference.

\section{The Pursuitworthiness Interpretation of Abduction}

\subsection{Prelude: The Mysterious Noise}


In 1964 and 1965, radio astronomers Arno Penzias and Robert Wilson were studying a radio wave emanating from the center of the Milky Way Galaxy using a horn-reflector antenna. The antenna was a basin-horn shaped receiver whose large end could be directed towards any given point to measure radio waves and hence the energy coming from there. Soon, however, they ran into a problem: even when they were targeting the 'dark' sky, where there should not be any source of energy, their device was detecting a 'noise' indicating the existence of a source of energy with a temperature around $4^{\circ} \mathrm{K}$, i.e., 4 degree above absolute zero or no-energy level.

Several hypotheses were suggested to explain the mysterious energy. Maybe it is caused by New York City that is quite close to the location of the antenna. But when Penzias and Wilson pointed the antenna towards the city, they found out that it was not 'hot' enough to cause that strength of signal. Some pigeons had also nested in the horn. Could they be the source of the mysterious energy? To find out, pigeons were evicted and their droppings were washed away. Again, no significant change was observed. Was the signal a result of an atomic test recently conducted near Hawaii? No. The remainder of the test's energy was decaying gradually, but after a long period of observation, there was no significant change in the mysterious signal's strength. After correcting for all of these factors, they could still detect $3.5^{\circ} \mathrm{K}$ in the dark sky.

The rest of the story is probably one of the happiest coincidences in the history of science. From a casual conversation, Penzias and Wilson heard about a theoretical work on the Big Bang. Robert Dickie and his team had predicted that if the universe had originated from the (very hot) Big Bang, a residual uniform temperature of $3.5^{\circ} \mathrm{K}$ should be throughout space. What Penzias and Wilson had detected was this cosmic microwave background (CMB) for which they won the Nobel Prize in $1978 .^{5}$

\subsection{Abduction is the Rule-based Ranking of Explanatory Hypotheses}

Faced with several hypotheses that can potentially explain a phenomenon, how do scientists decide which hypothesis is the worthiest one for further tests and observations? In other words, what type of reasoning should be used to determine the relative pursuitworthiness of available hypotheses? According to the Pursuitworthiness Interpretation, the answer is abduction. As McKaughan (2008, 452) puts it:

abductive reasoning is the label Peirce gives to his systematic attempts to think about the qualities that factor into decisions about whether investigating an idea looks promising or 
seems worthwhile. Abductive reasoning makes practically grounded comparative recommendations about which available hypotheses are to be tested.

A similar interpretation is suggested by Frankfurt (1958), Laudan (1980), Achinstein (1993), and Kapitan (1992, 1997, 2000).

As mentioned before, Peirce holds that for every phenomenon one can come up with several potential explanations among which, at best, only one is true. Since in order to find out the true explanation we should test the hypotheses, then "we have to select that one which is suitable for being tested by experiment" (NEM4.62, 1902). It is unreasonable to randomly pick hypotheses for testing because it results in the wasting of time, money, energy, etc. Thus, Peirce suggests that we should systematically rank the hypotheses to determine their priority for further examinations. This ranking "will include a preference for any one hypothesis over others which would equally explain the fact" $(6.525,1901)$. Abduction, according to the Pursuitworthiness Interpretation, consists of hypotheses-ranking and adaptation of the highest-ranking hypothesis for empirical tests.

Peirce holds that the criteria based on which hypotheses should be ranked are determined by economy in a broad sense, i.e., "economy of money, time, thought, and energy" (5.600, 1901; see also 6.528, 1901; 7.600, 1903). Many 'economic' desiderata that are mentioned by Peirce-e.g., testability, intelligibility, consistency with well-confirmed beliefs (7.220, 1901), refutability (or falsifiability) $(1.120,1896)$, broad scope, simplicity $^{6}(7.221,1901)$, and accuracy (W8: xli, 1890)— are called "theoretical virtues" or "epistemic values" by contemporary philosophers of science. (A notable exception is the cost of testing which is of the highest importance for Peirce but is not a theoretical virtue.) It is generally accepted that these virtues make theories and hypotheses better. ${ }^{7}$ Some even argue that they are truth-conducive. ${ }^{8}$ For Peirce, however, having a higher rank does not make an explanation closer to truth. ${ }^{9}$ It only means that its testing requires less expenditure of time, money, energy, etc. in comparison with a lower-ranking hypothesis.

In the discovery of $\mathrm{CMB}$, for instance, the 'New York hypothesis' was the best option to test first, because it was the easiest and the cheapest one to test; just turn the antenna towards New York City and see if it causes the noise. The 'atomic test hypothesis', however, was quite time-consuming, because its confirmation (or rejection) required long term observation. Even the 'pigeons hypothesis' required more work and time to test than the 'New York City hypothesis'. Furthermore, even if Penzias and Wilson knew about the 'Big Bang hypothesis' from the beginning, they would not declare its confirmation without first eliminating other hypotheses. ${ }^{10}$ 
Peirce insists that hypotheses-ranking is a calculated and a rule-governed procedure. For instance, in one of his many discussions about abduction and economy of research, he introduces six rules $(7.223-32,1901)$ for measuring relative pursuitworthiness of hypotheses and ranking them accordingly. Consequently, the Pursuitworthiness Interpretation clearly avoids the fatal non-formal objection to the Generative Interpretation-namely, abduction as interpreted by the Generative Interpretation, is not self-controlled and deliberate and hence it is not qualified as an inference. According to the Pursuitworthiness Interpretation, abduction can be considered an inference, because it is calculated and rule-governed and hence self-controlled and deliberate.

However, there are other objections that can be raised against the Pursuitworthiness Interpretation. In the following, I discuss a formal objection as well as several non-formal objections against this interpretation. I shall argue that at least one of the non-formal objections is fatal, because it shows that the Pursuitworthiness Interpretation results in a serious distortion of Peirce's philosophy of science in general and his account of scientific inquiry in particular.

\subsection{Objections against the Pursuitworthiness Interpretation}

Similar to the Generative Interpretation, the Pursuitworthiness Interpretation facing some formal objections according to which this interpretation does not make a good sense of the logical form of abduction. First, to satisfy the logical form of abduction, a hypothesis only needs to account for the explanandum. This by no means makes the hypothesis pursuitworthy. For instance, the hypothesis that I will be paid a million dollars if I write this paper accounts for my writing it. But this provides no reason to think that it is a pursuitworthy hypothesis to explain why I am writing this paper (Achinstein 1970, 92; Nickles 1980, 24). Second, the logical form says nothing about the economic desiderata that are so essential for the Pursuitworthiness Interpretation. Even worse, it seems that these desiderata cannot even be introduced to the logical form by adding, for instance, more premises to it. After making several such modifications to the logical form of abduction in this regard, Kapitan $(1992,1997)$ admits that either the form remains problematic for pursuitworthy based adaptation_or as he calls it "probational adaptations" (Kapitan 1992, 486)_of a hypothesis or it transforms into deduction, a fundamentally different type of inference.

Several non-formal objections can be also raised against the Pursuitworthiness Interpretation. First, one recurrent theme in Peirce's discussions of abduction is the indispensable role of great minds or geniuses in performing abductive inferences in science that results in finding the laws of nature $(5.604,1903 ; 7.202,1901)$. In this regard, Peirce's bar for being a genius is phenomenally 
high such that only "a Galileo, a Kepler, a Faraday, a Maxwell" can reach it. For Peirce, even Albert Michelson - a Nobel Laureate physicist and arguably the greatest American physicist contemporary with Peirce—did not have the required talent for performing those abductive inferences that result in formulating laws of nature $(7.279,1902)$. But if, as the Pursuitworthiness Interpretation suggests, abduction is simply a rule-based hypotheses-ranking process, everyone with normal intelligence and some practice should be able to perform it.

Secondly, the Pursuitworthiness Interpretation completely eliminates hypotheses-generation from abduction. But hypotheses-generation and pursuitworthiness have been given equal importance by Peirce (more on this in Section 4.1.2) such that sometimes, in one single paragraph, he talks about the inventive and the economic aspects of abduction:

[Abduction] matters much, for the reason that it originates every proposition. It is true that, however carelessly the abduction is performed, the true hypothesis will get suggested at last. But the aid which a correct logic can afford to science consists in enabling that to be done at small expenditure of every kind ... The whole service of logic to science, whatever the nature of its services to individuals may be, is of the nature of an economy. (7.220, fn. 18, my emphasis)

As much as it is unreasonable for the Generative Interpretation to ignore the role of economy in abduction, it is unreasonable for the Pursuitworthiness Interpretation to ignore hypothesesgeneration.

Finally, and more importantly, the Pursuitworthiness Interpretation distorts some important parts of Peirce's philosophy of science by completely jettisoning insight from his account of scientific inquiry. As we read, insight plays no role in abduction as understood by the Pursuitworthiness Interpretation. Since, on the one hand, for Peirce scientific inquiry consists only of abduction, deduction, and induction and, on the other hand, Peirce never talks about insight in the context of deduction or induction, the Pursuitworthiness Interpretation jettisons insight form scientific inquiry by expelling it from abduction. But insight is not simply a marginal idea in Peirce's theory of abduction. Rather, as I shall argue in the following, it is at the heart of Peirce's philosophy of science. In particular, insight plays a crucial role in Peirce's naturalistic explanation for the possibility of science and his view about the limitations of scientific knowledge that can be attained by 'classical' scientific method. 


\subsubsection{Insight and the Possibility of Science}

According to Peirce, without insight there is no science: "the existence of a natural instinct for truth is, after all, the sheet-anchor of science" $(7.220,1901)$. Briefly, Peirce argues that insight is a necessary condition for discovering laws of nature which, in turn, is an integral part of scientific method. Without scientific method there is no science. Therefore, insight is a necessary condition for science. Now let's explore this argument.

Science is "a mode of life whose single animating purpose is to find out the real truth, which pursues this purpose by a well-considered method" $(7.54,1902)$. To emphasize on the import of scientific method in defining what science is, Peirce mentions that following Kant, most of his contemporaries consider "Systematic character" of science as its definitive feature. Yet, he agrees with ancient Greeks and Bacon in taking scientific method as what makes science distinct from other types of knowledge $(7.49$ and $7.54,1902)$. But an integral part of scientific method is discovering laws of nature $(7.83,1902)$. Therefore, without discovering laws of nature there is no scientific method and hence no science.

The discovery of laws of nature is possible because the human mind is a part of nature and hence it has been formed and developed by nature's laws. As a result, it is reasonable to expect that a "natural disposition" (7.381, n.19) has been formed in our minds enabling us to discover the laws of nature. This disposition is insight:

if the universe conforms, with any approach to accuracy, to certain highly pervasive laws, and if man's mind has been developed under the influence of those laws, it is to be expected that he should have a natural light, or light of nature, or instinctive insight, or genius, tending to make him guess those laws aright, or nearly aright. (5.604, 1903; see also 5.591, 1903; 7.508, 1898; 7.687, 1903)

So insight, the faculty of guessing laws of nature, is a condition of possibility of science.

Why does Peirce think that developing insight is a reasonable expectation? Many activities necessary for the survival of our ancestors—such as hunting or farming and reproduction—requires sound judgments about their physical environment and their fellow beings. To come up with such judgments without having "a tendency to conjecture rightly" $(7.679,1903)$, our ancestors had to test all possible hypotheses about hunting, say, to see which one was true. An overwhelming majority of such hypotheses, however, would have caused them severe damage (for instance, imagine them 
testing 'I can hunt mammoths with bare hands' or 'All types of flesh are nutritious'). With a "tendency toward preferring truthful hypotheses [i.e., insight]" $(7.680,1903)$, however, they had to test only a handful of plausible hypotheses. So possessing insight brings about an obvious evolutionary advantage and thus it is a reasonable expectation from a biological point of view. But since preferring good hypotheses is not possible without preferring, at least implicitly, the laws of nature upon which such hypotheses are grounded, it is also reasonable to expect that we have developed a tendency to make good guesses about laws of nature. This makes insight the kernel of Peirce's naturalistic explanation for possibility of scientific knowledge.

\subsubsection{Insight and the Limits of 'Classical' Scientific Method}

Deduction and induction do not impose any intrinsic limits on science. Of course we might not be able to form the relevant deductive inferences or we might not have the technology, money, and time to conduct the required tests. But these are practical restrictions. Nothing intrinsic to deduction or induction dictates them. Abduction as a completely rule-governed process of ranking rival hypotheses-i.e., abduction as understood by the Pursuitworthiness Interpretation-does not impose any intrinsic limits on the scope and the depth of scientific knowledge either. However, as we shall see soon, Peirce explicitly claims that abduction is inherently restricted and has already imposed limits on the scope of the depth of the scientific knowledge of his time. So abduction as understood by the Pursuitworthiness Interpretation cannot be true.

Where do the limitations on scientific knowledge of Peirce's time come from? Peirce holds that, in some areas, insight generates less and less truthful hypotheses. This makes the prospect of discovering true explanations of natural phenomena in those areas dimmer and dimmer, hinders the progress of science more and more, and finally sets up a boundary for it. The problem here is rooted in the original purpose of insight. Since insight is developed for survival, it stops functioning well about matters of no survival value. This happens in two general cases.

First, to the extent that science is dependent on insight, it is limited in scope. Since our ancestors' struggle for survival was limited to their relationships with their physical surroundings and with other human beings, only two types of good guesses were required for their survival. First, "some notions, however crude and concrete, of force, matter, space, and time" and second "some notion of what sort of objects ... [our] fellow-beings are, and of how they will act on given occasions" (2.753, 1893). Insight has evolved only to make good guesses in these two areas. Therefore, "Man has thus 
far not attained to any knowledge that is not in a wide sense either mechanical or anthropological in its nature, and it may be reasonably presumed that he never will” $(2.753,1893)$.

Second, in an important discussion in lecture seven of The Cambridge Conferences Lectures (1898), Peirce claims that reliance on insight limits the depth of scientific knowledge. The struggle for survival happens on the 'surface' of nature. For example, knowledge of ordinary properties of mundane physical objects, required for making tools for hunting or farming, had a great survival value for our ancestors. Therefore, those with incompetent insights who made bad guesses in these regards could not survive. But since no knowledge of the cosmos or atoms was needed for survival, insight did not have to make any guesses about them. Even if it had, making bad guesses would not have been punished by natural selection. Hence,

as we penetrate further and further from the surface of nature, instinct ceases to give any decided answers; and if it did there would no longer be any reason to suppose its answers approximated to the truth. $(7.508,1898)$

For someone familiar with the science (especially physics) at the end of the nineteenth century, saying that we cannot attain a reliable knowledge about the 'deep' structure of nature is an odd claim. At that time, there were important theories about molecules and atoms. In fact, a year before Peirce's making the above claim, J.J. Thomson had discovered the electron, the first known subatomic particle (Falconer 1987, 241). Was Peirce unaware of these developments? Obviously he was not. Peirce was, above all, a man of science. In the same lecture, he discusses scientific theories about atoms and molecules. However, he also correctly recognizes that such theories are developed "based on the assumption that the molecules ... are like large masses of ordinary matter" $(7.507,1898)$. This is an accurate remark. At that time, molecules and atoms were considered to be similar to tiny billiard balls that are moving around and colliding with one another. For instance, describing the behavior of gases, Maxwell $(1872,287)$ writes "When two molecules come within a certain distance of each other, a mutual action takes place between them, which may be compared to the collision of two billiard balls." Yet, Peirce holds that

that similarity has its limits. We already have positive proof that there are also wide dissimilarities; and furthermore it seems clear that nearly all that method could teach has been already learned. $(7.507,1898)$ 
Is Peirce mistakenly declaring 'the end of science' here? After all, at that time, the idea that science (or at least physics) has probably reached its end was not an outlandish idea at least in the United States. For instance, only four years earlier, one of the greatest American physicists Albert Michelson had claimed that

it seems probable that most of the grand underlying principles have now been firmly established and that further advances are to be sought chiefly in the rigorous application of these principles to all the phenomena which come under our notice. $(1894,15)$

Is Peirce making a similar claim? I do not think so.

Peirce's claim is more nuanced than Michelson's. In the passage quoted above $(7.507,1898)$, Peirce does not claim that the scientific knowledge has reached its limits. Rather, he explicitly says that "all that method could teach has been already learned" (7.507, 1898; my emphasis). What does Peirce mean by "that method"? He means the method that has been developed for attaining knowledge about ordinary medium sized objects and examines 'extra-ordinary' entities—e.g., atoms and the cosmos—only in terms of their similarities with ordinary objects. But, as discussed before, the method that has been developed for ordinary objects heavily relies on insight and the evolutionary advantages that it provides. Therefore, Peirce does not claim that scientific knowledge is exhausted. Rather, he thinks that the capacity of the method that relies on insight for exploring deeper layers of nature is depleted.

Moreover, in the same lecture, Peirce says that as "a physicist and a chemist" and "a student of methods of science", he looks for "a broad plan for any further grand advance" to attain new knowledge about atoms and molecules $(7.506,1898)$. This would be a futile search, if he believed that there is nothing more to learn. But it would make perfect sense if Peirce looks for a new method, one that goes above and beyond our instinctive insight. The impressiveness of this demand becomes clearer once we recall that one of the common characteristics of post-classic paradigms in physicswhether quantum mechanics or relativity—is avoiding a reliance on common sense intuitions which draw similarities between the subatomic (and cosmic) entities and medium-sized objects. ${ }^{11}$

If my arguments are sound, insight is by no means a marginal idea that can be left out of Peirce's theory of abduction. Rather, it is at the heart of two important and interesting parts of his philosophy of science concerning the naturalistic explanation of possibility of science and the limits of the scientific method of his time. Since Peirce never discuses insight in the context of deduction 
or induction, ruling it out from abduction results in its expelling from Peirce's account of scientific inquiry, which is a serious distortion of his philosophy of science.

\section{The Unified Interpretation of Abduction}

\subsection{The Exegetical Dichotomy: Insight or Inference?}

So if the Generative Interpretation is true, abduction fails to be an inference. The Pursuitworthiness Interpretation makes abduction an inference but with tremendous cost. This exegetical predicament is very well-known in the literature. Anderson is addressing this dilemma when he says "Peirce quite explicitly stated that abduction is both an insight and an inference. This is a fact to be explained, not to be explained away" $(1987,33)$. Kapitan is recognizing this problem when he writes "Juggling inference with instinct calls for careful exegesis" (1990, 504). Burks (1946, 302-3) evades this predicament when he claims that Peirce's statements about the instinctive nature of insight should not be taken literally. And when Paavola claims that "Peirce never satisfactorily resolved the relationship between instinct and inference" (2005, 149), he addresses this quandary. I think, however, that 'the Generative Interpretation vs. the Pursuitworthiness Interpretation' (and hence 'insight vs. inference' and 'instinctive generation vs. rule-based ranking') is a false exegetical dichotomy. In the following, I argue that these two interpretations can and should be unified.

\subsection{Resolving the Exegetical Dichotomy: Insight and Inference}

According to the Unified Interpretation, abduction consists of two main phases. ${ }^{12}$ After observing a surprising phenomenon, in the first phase of abduction insight generates a few plausible explanatory hypotheses to explain the phenomenon. As mentioned earlier, insight generates these hypotheses through its inventive function. Moreover, although there are 'trillions of trillions' of possible-toimagine hypotheses that insight can come up with, it only generates a few plausible ones because of its restrictive function. Let's call this phase hypotheses-generation.

Hypotheses-generation is creative and 'originary' and makes abduction ampliative. Moreover, not everyone has a similar creativity and talent in coming up with original hypotheses. Only a handful of geniuses can come up with hypotheses as remarkable as the law of inertia or universal gravitation. Thus, hypothesis-generation also makes abduction ingenious. Yet, since hypothesisgeneration is instinctive, it is neither deliberate nor self-controlled nor rule-based.

The second phase of abduction is ranking the generated hypotheses based on economic considerations to determine their relative pursuitworthiness. Let's call this phase hypotheses-ranking. 
Hypotheses-ranking is rule-based, deliberate, and self-controlled. But it is neither 'originary' nor ingenious.

\subsection{The Unified Interpretation and the Objections against the Pursuitworthiness Interpretation and the Generative Interpretation}

How good is the Unified Interpretation? In this section, first I argue that none of the non-formal objections against the Generative Interpretation and the Pursuitworthiness Interpretation can be raised against the Unified Interpretation. Then I introduce my solution for the formal objection(s) in general.

\subsubsection{The Unified Interpretation and the Non-Formal Objections}

I mentioned three non-formal objections to the Pursuitworthiness Interpretation. It cannot explain Peirce's emphasis on the role of great genius in abduction. It ignores the strong association that Peirce draws between abduction and hypotheses-generation-and hence the ampliative nature of abduction. Finally, it excludes the essential notion of insight from abduction in particular and scientific reasoning in general. None of these objections can be raised against the Unified Interpretation, because according to this interpretation, phase one of abduction generates new hypotheses. Thus, abduction is ampliative. Moreover, since phase one requires the inventive function of someone's insight, the creativity of a genius is needed for making breakthroughs in science. Finally, the Generative Interpretation takes both the transcendental status of insight in making science possible and the restrictions that it imposes on science into account.

The non-formal objection to the Generative Interpretation states that insight is an instinctive faculty and hence its function is neither deliberate nor self-controlled. But inferences are essentially deliberate and self-controlled. Therefore, hypotheses-generation cannot be an inference. I agree. Hypotheses-generation alone does not constitute an inference. It can, however, constitute a phase of an inference because an inference can have an uncontrolled and undeliberate phase. Peirce holds that an inference consists of three steps: colligation, observation, and judgment $(2.444,1893)$. In deduction, colligation is bringing premises together to contemplate the resulting "conjunctive proposition" $(2.442,1893)$. If successful, this leads to an observation that if the premises are true, then the conclusion is true $(7.536,1898)$. Next follows the judgment, that is, accepting the conclusion. Although colligation and judgment are voluntary and controlled, observation is uncontrolled, involuntary (Kapitan 1990, 500-501), and involves "a peculiar sense of constraint" 
(7.459, 1893), because in a valid deduction one cannot help but 'to observe' the truth of the conclusion if the premises are true. So even deductive inference has an uncontrolled and undeliberate phase.

In "The First Rule of Logic" (1898), Peirce describes abduction in a very similar way. Abduction "begins always with colligation ... of a variety of separately observed facts about the subject of the hypothesis ... And then comes an Observation" (5.581, 1898). Observation in general is becoming "conscious of something" by an "occult power" or a "force majeure" that enforces it on us when we are contemplating an object. In an "External observation" when we literally see something, we yield to that power "deliberately." In abduction, however,

the surrender which we make $\ldots$ is a surrender to the Insistence of an Idea. The hypothesis, as the Frenchman says, c'est plus fort que moi. It is irresistible; it is imperative. We must throw open our gates and admit it at any rate for the time being. (5.581, 1898, my emphasis)

Thus, not only does abduction include observation, but also, as the passage suggests, this observation is becoming aware of a hypothesis and it is irresistible and must be admitted at any rate. In other words, it is involuntary and not under our control.

Peirce's emphasis on the involuntary aspect of abductive inference and its connection with the instinctive nature of hypotheses-generation can be also seen in his most mature works on abduction. For instance, in his description of abduction in "The Neglected Argument for the Reality of God" (1908), he writes:

we cannot help accepting the conjecture at such a valuation as that at which we do accept it; ... But far from constituting, by itself, a logical justification such as it becomes a rational being to put forth, this pleading, that we cannot help yielding to the suggestion, amounts to nothing more than a confession of having failed to train ourselves to control our thoughts. It is more to the purpose, however, to urge that the strength of the impulse is a symptom of its being instinctive. (EP2.443, 1908)

\subsubsection{The Unified Interpretation and the Logical Form of Abduction}

Does the Unified Interpretation make a good sense of the logical form of abduction? I have a radical but justifiable approach to the importance of the logical form of abduction in Peirce's theory which makes this question unsubstantial: the logical form of abduction is at best marginal and very probably of no significance in Peirce's mature theory of abduction. So it should never be our 
exegetical locus classicus. Rather, our interpretation of Peirce's theory of abduction should be structured around notions such as insight and economy of research-and hence hypothesesgeneration and hypotheses-ranking. If we could come up with an interpretation in which the logical form could peacefully coexist with these notions, so much the better. Otherwise, insight and economy should be the pillars of interpretation, and the logical form must go.

My approach is the exact opposite of the one adopted by some prominent commentators. When Frankfurt (1958) claims that abduction cannot generate new hypotheses, he actually shows that the logical form of abduction cannot make sense of hypotheses-generation (see 2.2.1). When Achinstein $(1970,92)$ and Nickles $(1980,24)$ claim that abduction is too permissive to be of any use, they simply show that its logical form permits all sorts of 'crazy' hypotheses (see 2.4.1). But no one puts more emphasis on the logical form of abduction than Kapitan who tries to understand all aspects of abduction in the light of its logical form. For instance, he holds that the moment of creativity in abduction should only be sought in the premise in which the hypothesis first occurs. But then he ends up concluding that Peirce does not offer a successful solution to the problem of creativity of abduction (Kapitan 1990). He also tries to introduce the plausibility of hypotheses and economic considerations, in terms of new premises, to the logical form of abduction which results in its transformation into deduction (Kapitan 1992, 1997).

But why should the interpretation of Peirce's mature theory of abduction be structured around insight and economy and not its logical form? For two reasons: first, in his mature theory of abduction, Peirce's emphasis on insight and economy is significantly stronger than his emphasis on the logical form of abduction. Second, we have textual evidence against understanding abduction in terms of a formal logical relation between some premises and a conclusion.

As for the first reason, based on a fundamental change in Peirce's theory of abduction in the 1890s, Fann (1970) divides this theory to two periods: (i) the early theory from 1859 to 1890 and (ii) the later theory (or his mature theory) from 1890 to 1914. Peirce's emphasis on the role of insight in abduction begins even before his mature theory. For instance, his discussion of abduction in "A Theory of Probable Inference" (1883) includes some passages about the necessity of insight for possibility of scientific knowledge (e.g., 2.753-54). With respect to the economic considerations, although their intimate relation with abduction was not recognized by Peirce until after 1891 (Fann 1970, 24), their critical role in science was known by Peirce at least since 1876, when he published "Note on the Theory of the Economy of Research" (7.139-161). 
The story of the logical form(s) of abduction is very different though. In his early theory, Peirce suggests several forms for abduction which are actually "different permutations of the premisses and conclusions of a syllogism" (Levi 1995, 72). Yet, in 1902, in a retrospective reflection on his early theory, he talks about a "capital error" he committed in confusing abduction with one type of induction. The first reason he gives for this error is that he "was too much taken up in considering syllogistic forms" which he "made more fundamental than they really are" $(2.102,1902)$. For this reason, in his later theory Peirce totally abandons the project of 'formalizing' abduction with one single exception. As mentioned before, in his Harvard Lectures, Peirce suggests the "a perfectly definite logical form" $(5.189,1903)$ of abduction. But not only does not he mention this form anymore in his later works, but also in 1910, in an important letter to Paul Carus, once again he suggests that abduction cannot be understood in terms of a formal relation between some premises and a conclusion. After describing his discovery of trichotomy-i.e., three fundamental types of inference-he adds

The general body of logicians had also at all times come very near recognizing the trichotomy. They only failed to do so by having so narrow and formalistic a conception of inference (as necessarily having formulated judgments for its premises) that they did not recognize Hypothesis (or, as I now term it, retroduction) as an inference. (8.228, 1910; Peirce's emphasis)

Of course if Peirce still believed that abduction had a logical form, let alone an already discovered one, he would not have blamed logicians for their narrow, formal conception of inference, in terms of premises and conclusions, which prevented them from recognizing abduction as a type of inference.

If my arguments are sound, then hypotheses-generation and hypotheses-ranking (together with the consequent adoption of the highest-ranking hypothesis) are all included within abduction. Moreover, as long as the Unified Interpretation (or any other interpretations) can make perfect sense of hypotheses-generation and hypotheses-ranking, inconsistency with the logical form of abduction is not really a problem. Therefore, the formal objections against the Generative Interpretation and the Pursuitworthiness Interpretation are overruled as well. But the fatal problems of these two interpretations were not formal. The Generative Interpretation failed to qualify abduction as a type of inference and the Pursuitworthiness Interpretation, inter alia, distorted important aspects of Peirce's philosophy of science by excluding insight from abduction. But none of the informal 
objections against the Generative and the Pursuitworthiness Interpretations can be raised against the Unified Interpretation.

\footnotetext{
${ }^{1}$ See Section 4.2.1 of this paper.
}

${ }^{2}$ Peirce traces the origin of abduction back to the notion of apagōge in Aristotle's Prior Analytics. Flórez (2014) argues that he is mistaken and apagogē is unrelated to what Peirce calls abductive inference.

${ }^{3}$ Peirce uses "inference" and "reasoning" interchangeably. In this paper, I follow him.

${ }^{4}$ References to Collected Papers of Charles Sanders Peirce (Peirce 1931-1935; 1958) are of the form (volume number. paragraph number, date), e.g. $(5.591,1903)$. References to The New Elements of Mathematics (Peirce 1976) are of the form (NEM volume number. page number, date), e.g. (NEM4.62, 1902). References to The Essential Peirce: Selected Philosophical Writings (Peirce 1998) are of the form (EP volume number. page number, date), e.g. (EP2.187, 1903). References to Writings of Charles S. Peirce: A Chronological Edition (Peirce 2010) are of the form (W volume number: page number, date), e.g., (W8: 217, 1892).

${ }^{5}$ For a detailed discussion about the detection of CMB by Penzias and Wilson, see Wilson's Nobel Lecture (1979) and Partridge (1995, 47-50).

${ }^{6}$ Peirce distinguishes between two types of simpleness of a hypothesis (see 7.220, 1901). The first type which he calls "simplicity" is a "purely intrinsic" characteristic. That is, one does not need to compare one hypothesis with others in order to determine whether it has simplicity or not. Rather, such hypotheses

naturally recommend themselves to the mind, and make upon us the impression of simplicitywhich here means facility of comprehension by the human mind—of aptness, of reasonableness, of good sense $(7.220$, 1901; see also EP2.444, 1908)

The second type of simpleness which he calls "incomplexity", however, is relational and can be determined only by comparing different hypotheses.

${ }^{7}$ See, for instance, Kuhn (1977), Quine and Ullian (1978, chap. vi), and Hempel (1979).

${ }^{8}$ See, for instance, Newton-Smith (1981, 226-32), McMullin (1996), and Lipton (2004, chap. 9).

9 In a discussion on economy of research, Peirce $(7.220,1901)$ calls one category of economic considerations "the value of the thing [i.e., the hypothesis] proposed, in itself" which includes "those considerations which tend toward an expectation that a given hypothesis may be true." He does not clearly specify which desiderata are included within this category. (It seems that intrinsic simplicitysee not 6-and consistency with well-established beliefs are two of them.) Prima facie, this might suggest that since considerations pertaining to the value of a hypothesis in itself say something about its likelihood, they should be epistemic as well as economic. But a careful examination shows that this is not correct. First, according to Peirce:

experience shows that likelihoods are treacherous guides. Nothing has caused so much waste of time and means, in all sorts of researches, as inquirers' becoming so wedded to certain likelihoods as to 
forget all the other factors of the economy of research; so that, unless it be very solidly grounded, likelihood is far better disregarded, or nearly so. $(7.220,1901)$

Second, even if we are aware of some "positive facts which render a given hypothesis objectively probable," these facts only "recommend it [i.e., the hypothesis] for inductive testing" which, obviously, is quite different from recommending the truth of a hypothesis.

${ }^{10}$ In their final paper, Penzias and Wilson did not mention the 'Hot Big Bang' hypothesis at all. As Wilson $(1979,871)$ explains in his Nobel Lecture:

Arno [Penzias] and I were careful to exclude any discussion of the cosmological theory of the origin of background radiation from our letter because we had not been involved in any of that work. We thought, furthermore, that our measurement was independent of the theory and might outlive it.

However, they published the results of their observations side-by-side with Dickie and his team's paper in the Astrophysical Journal. In their paper, they mention that "A possible explanation for the observed excess noise temperature" (Penzias and Wilson 1965, 420) is provided in Dickie and his team's paper.

${ }^{11}$ For two interesting discussions about how the world as described by contemporary science is different form the world as described by our instincts and common sense intuitions, see Reichenbach (1951, chap. 11) and Wolper (1992, chap. 1).

12 To the best of my knowledge, two commentators endorse views about abduction that does not limit it to a single-phase procedure. Delaney discusses "two different moments" of abduction that include "original generation and recommendation of explanatory hypotheses" (1982, 177-78, see also 1993, 40). Mcauliffe (2015) also holds that abduction "need not be a process with only one step" (2015, 304) and it "generates and chooses hypotheses to test" (2015, 301, my emphasis). 


\section{References}

Achinstein, Peter. 1970. "Inference to Scientific Laws." In Historical and Philosophical Perspectives of Science, edited by Roger H. Stuewer, 87-111. Minneapolis: University of Minnesota Press.

—. 1993. "How to Defend a Theory Without Testing It: Niels Bohr and the 'Logic of Pursuit." Midwest Studies In Philosophy 18 (1): 90-120.

Anderson, Douglas R. 1986. "The Evolution of Peirce's Concept of Abduction.” Transactions of the Charles S. Peirce Society 22 (2): 145-64.

Anderson, Douglas R. 1987. Creativity and the Philosophy of C. S. Peirce. Dordrecht: Springer Netherlands.

Burks, Arthur W. 1946. "Peirce's Theory of Abduction.” Philosophy of Science 13 (4): 301-6.

Burton, Robert G. 2000. "The Problems of Control in Abduction." Transactions of the Charles $S$. Peirce Society 36 (1): 149.

Campos, Daniel G. 2009. "On the Distinction between Peirce's Abduction and Lipton's Inference to the Best Explanation." Synthese 180 (3): 419-42.

Davis, William Hatcher. 1972. Peirce’s Epistemology. The Hague: Nijhoff.

Delaney, C. F. 1982. "Peirce on 'Simplicity' and the Conditions of the Possibility of Science." In History of Philosophy in the Making: A Symposium of Essays to Honor Professor James D. Collins on His 65th Birthday, edited by James Daniel Collins and Linus J. Thro, 177-94. Washington, D.C: University Press of America.

- 1993. Science, Knowledge, and Mind: A Study in the Philosophy of C.S. Peirce. Notre Dame: University of Notre Dame Press.

Falconer, Isobel. 1987. "Corpuscles, Electrons and Cathode Rays: J. J. Thomson and the 'Discovery of the Electron." The British Journal for the History of Science 20 (3): 241-76.

Fann, K. T. 1970. Peirce's Theory of Abduction. The Hague: Martinus Nijhoff.

Flórez, Jorge Alejandro. 2014. "Peirce's Theory of the Origin of Abduction in Aristotle." Transactions of the Charles S. Peirce Society: A Quarterly Journal in American Philosophy 50 (2): $265-80$.

Frankfurt, Harry G. 1958. "Peirce's Notion of Abduction.” The Journal of Philosophy 55 (14): 59397.

Hanson, Norwood Russell. 1958. Patterns of Discovery: An Inquiry into the Conceptual Foundations of Science. Cambridge: Cambridge University Press.

Hempel, Carl G. 1979. "Scientific Rationality: Analytic vs. Pragmatic Perspectives." In Rationality To-Day/La Rationalite Ajiourd'hui, edited by T. S. Geraets, 46-58. Ottawa: The University of Ottawa Press.

Hintikka, Jaakko. 1998. "What Is Abduction? The Fundamental Problem of Contemporary Epistemology." Transactions of the Charles S. Peirce Society 34 (3): 503.

Hoffmann, Michael. 1999. "Problems with Peirce's Concept of Abduction." Foundations of Science 4 (3): 271-305. 
Kapitan, Tomis. 1990. "In What Way Is Abductive Inference Creative?" Transactions of the Charles S. Peirce Society 26 (4): 499-512.

1992. "Peirce and the Autonomy of Abductive Reasoning." Erkenntnis (1975-) 37 (1): 126.

. 1997. "Peirce and the Structure of Abductive Inference." In Studies in the Logic of Charles Sanders Peirce, edited by Nathan Houser, Don D. Roberts, and James Van Evra, 477-496. Bloomington: Indiana University Press.

—. 2000. "Abduction as Practical Inference." In The Digital Encyclopedia of Peirce Studies, edited by M. Bergman and J. Queiroz, New Edition. http://www.commens.org/encyclopedia/article/kapitan-tomis-abduction-practical-inference.

Kuhn, Thomas S. 1977. "Objectivity, Value Judgment, and Theory Choice." In The Essential Tension: Selected Studies in Scientific Tradition and Change, 320-39. Chicago: University of Chicago Press.

Laudan, Larry. 1980. "Why Was the Logic of Discovery Abandoned?" In Scientific Discovery, Logic, and Rationality, 173-83. Dordrecht, The Netherlands: Springer.

Levi, Isaac. 1995. "Induction According to Peirce." In Peirce and Contemporary Thought: Philosophical Inquiries, edited by Kenneth Laine Ketner, 59-93. New York: Fordham University Press.

Lipton, Peter. 2004. Inference to the Best Explanation. 2nd ed. London: Routledge.

Martínez, Alberto A. 2011. Science Secrets: The Truth about Darwin's Finches, Einstein's Wife, and Other Myths. Pittsburgh: University of Pittsburgh Press.

Maxwell, James Clerk. 1872. Theory of Heat. 3rd ed. London: Longmans, Green, and Co.

McAuliffe, William H. B. 2015. "How Did Abduction Get Confused with Inference to the Best Explanation?" Transactions of the Charles S. Peirce Society 51 (3): 300-319.

McKaughan, Daniel J. 2008. "From Ugly Duckling to Swan: C. S. Peirce, Abduction, and the Pursuit of Scientific Theories." Transactions of the Charles S. Peirce Society 44 (3): 446-68.

McMullin, Ernan. 1996. "Epistemic Virtue and Theory Appraisal." In Realism in the Sciences, edited by Igor Douven and Leon Horsten, 13-34. Leuven, Belgium: Leuven University Press.

Michelson, Albert. 1894. "Some of the Objects and Methods of Physical Science." Quarterly Calendar 3 (2): 12-15.

Minnameier, Gerhard. 2004. "Peirce-Suit of Truth - Why Inference to the Best Explanation and Abduction Ought Not to Be Confused.” Erkenntnis 60 (1): 75-105.

Newton-Smith, W. H. 1981. The Rationality of Science. London: Routledge.

Nickles, Thomas. 1980. "Introductory Essay: Scientific Discovery and the Future of Philosophy of Science." In Scientific Discovery, Logic, and Rationality, 1-59. Dordrecht: Springer.

Paavola, Sami. 2005. “Peircean Abduction: Instinct or Inference?” Semiotica 2005 (153-1/4): 131154.

Partridge, R. B. 1995. 3 K: The Cosmic Microwave Background Radiation. New York: Cambridge University Press. 
Peirce, Charles Sanders. 1931-1935. Collected Papers of Charles Sanders Peirce. Edited by Charles Harteshorne and Paul Weiss. Vol. 1-6. 8 vols. Cambridge, MA: Harvard University Press.

- 1958. Collected Papers of Charles Sanders Peirce. Edited by Arthur W. Burks. Vol. 7-8. 8 vols. Cambridge, MA: Harvard University Press.

- 1976. The New Elements of Mathematics. Edited by Carolyn Eisele. Vol. 4. 4 vols. The Hague: Mouton.

— 1998. The Essential Peirce: Selected Philosophical Writings. Vol. 2. 2 vols. Bloomington: Indiana University Press.

-. 2010. Writings of Charles S. Peirce: A Chronological Edition, Volume 8: 1890-1892. Bloomington: Indiana University Press.

Penzias, A. A., and R. W. Wilson. 1965. "A Measurement of Excess Antenna Temperature at 4080 Mc/s." The Astrophysical Journal 142 (July): 419.

Quine, W. V., and J. S. Ullian. 1978. The Web of Belief. 2nd ed. New York: McGraw-Hill.

Reichenbach, Hans. 1951. The Rise of Scientific Philosophy. Berkeley: University of California Press.

Turrisi, Patricia A. 1990. "Peirce's Logic of Discovery: Abduction and the Universal Categories." Transactions of the Charles S. Peirce Society 26 (4): 465-97.

Wilson, R. W. 1979. “The Cosmic Microwave Background Radiation.” Science 205 (4409): 86674.

Wolpert, Lewis. 1992. The Unnatural Nature of Science. Cambridge: Harvard University Press. 